\title{
Pengaruh Model Pembelajaran Kooperatif Tipe Example Non Example Berbantuan Kertas Duplek Terhadap Peningkatan Pemahaman Konsep Bangun Ruang
}

\author{
Nur Kummala, Pujilestari \\ Pendidikan Matematika FSST UNDIKMA \\ nurkummala@gmail.com
}

\begin{abstract}
The purpose of this study was to determine whether or not there is an effect of the example non example cooperative learning model assisted by duplex paper to increase understanding of the concept of building. This research design used Postest Only Control Design. The research sample was 70 students who were selected using purposive sampling technique. The experimental class uses the example non example learning model, while the control class uses a conventional learning model. Based on the result of the research from the normality and homogeneity test with the assistance of spss version 16 from the two data groups of the sample, both data were normal and homogeneous, so that the hypothesis testing used the t-test assisted by spss version 16. From the data results obtained a value (2-sig. Tailed. ) $<0.05$, namely $0.000<0.05$ at the 5\% significance level, then $H_{a}$ is accepted and $\mathrm{H}_{0}$ is rejected, which means that there is an effect of the example non example type of learning model on students' conceptual understanding. This shows that the use of the example non example type of learning model for students' understanding of concepts gave better result than using the conventional learning model.
\end{abstract}

Keywords: Example Non Example, Understanding concepts

Abstrak: Tujuan penelitian ini adalah untuk mengetahui ada atau tidak pengaruh model pembelajaran kooperatif tipe example non example berbantuan kertas duplek terhadap peningkatan pemahaman konsep bangun ruang. Desain penelitian ini menggunakan Postest Only Control Design. Sampel penelitian berjumlah 70 siswa yang dipilih dengan menggunakan teknik sampling purposive. Pada kelas eksperimen menggunakan model pembelajaran tipe example non example, sedangkan kelas kontrol menggunakan model pembelajaran konvensional. Berdasarkan hasil penelitian dari uji normalitas dan homogenitas dengan berbantuan spss versi 16 dari kedua data kelompok sampel, bahwa kedua data normal dan homogen, sehingga pengujian hipotesis digunakan uji-t dengan berbantuan spss versi 16. Dari hasil data diperoleh nilai (2-sig. tailed) $<0,05$ yaitu $0,000<0,05$ pada taraf signifikansi $5 \%$, maka $\mathrm{H}_{\mathrm{a}}$ diterima dan $\mathrm{H}_{0}$ ditolak yang berarti bahwa terdapat pengaruh model pembelajaran tipe example non example terhadap pemahaman konsep siswa. Hal tersebut menunjukkan bahwa penggunaan model pembelajaran tipe example non example terhadap pemahaman konsep siswa memberikan hasil yang lebih baik dari pada menggunakan model pembelajaran konvensional.

Kata kunci: Example Non Example, pemahaman konsep

\section{PENDAHULUAN}

Dalam Undang-Undang No.20 Tahun 2003 tentang Sistem Pendidikan Nasional menyatakan bahwa pendidikan adalah usaha sadar dan terencana untuk mewujudkan suasana proses belajar dan proses pembelajaran agar peserta didik secara aktif mengembangkan potensi dirinya untuk memiliki kekuatan spiritual keagamaan pengendalian diri, kepribadian, kecerdasan akhlak mulia serta keterampilan yang diperlukan dirinya, masyarakat bangsa dan Negara (Budiarti, dkk. 2017:21). Pendidikan yang baik dapat mewujudkan sumber daya manusia yang bermutu. Faktor yang mempengaruhi kualitas suatu Negara adalah tergantung dari pendidikan 
yang baik dan bermutu, akan tetapi berbagai problematika di Indonesia muncul tidak hanya dalam permasalahan konsep pendidikan melainkan muncul mulai dari masalah kurikulum, kualitas, kompetensi, bahkan kompetensi kepemimpinan menambah kompleknya problematika pendidikan di Indonesia (Afifah, 2015:41).

Menurut James (dalam Hasratuddin, 2014:30) matematika adalah ilmu tentang logika mengenai bentuk, susunan, besaran dan konsep-konsep berhubungan lainnya dengan jumlah banyak yang terbagi kedalam tiga bidang yaitu, aljabar, analisis dan geometri. Depertemen pendidikan nasional (dalam Pranata, 2016:34) menyatakan ada beberapa aspek yang perlu dikembangkan dalam pembelajaran matematika, diantaranya adalah pemahaman konsep, pemecahan masalah serta penalaran dan komunikasi. Tetapi pada kenyataannya, permasalahan prestasi matematika siswa masih sangat rendah. Sesuai dengan hasil penelitian yang dilakukan oleh Trends in Internasional Mathematics and Science Study (TIMSS) dan Program for International Assessment of Student (PISA) menunjukkan bahwa prestasi belajar matematika siswa SMP di Indonesia yang diperoleh adalah sebagai berikut: tahun 1999 mendapat ranking 34 dari 38 negara, tahun 2004 mendapat ranking 35 dari 46 negara, tahun 2007 mendapat ranking 36 dari 48 negara, dan tahun 2009 mendapat ranking 61 dari 65 negara. (Yuntawati, 2017: 127). Menurut Wardhani dan Rumiati (dalam Fu'ad, 2013:6) Topik soal dari domain konten geometri yang diujikan TIMSS pada siswa SMP di Indonesia, yaitu mengenai bentukbentuk geometri, pengukuran, letak dan perpindahan. Dari laporan hasil studi TIMSS pada tahun 2007 bahwa siswa yang menjawab benar hanya $25,2 \%$. Jadi dapat disimpulkan bahwa siswa Indonesia lemah dalam menyelesaikan soal-soal geometri dan siswa masih banyak yang mengalami kesulitan dalam menyelesaikan soal tersebut.
Berdasarkan hasil observasi terhadap prestasi belajar siswa dan wawancara dengan guru mata pelajaran matematika di SMAN 7 MATARAM, dimana hasil wawancara guru matematikanya mengatakan bahwa tidak pernah menggunakan model pembelajaran Kooperatif Tipe Example Non Example sebelumnya dan sebagian besar strategi yang diterapkan oleh guru matematika di SMAN 7 Mataram masih berpusat pada guru dan belum banyak melibatkan peran siswa di kelas. Hal ini mengakibatkan siswa dalam memahami pelajaran cenderung tidak bertahan lama. Pada umumnya, siswa belum memiliki interaksi belajar yang kooperatif, artinya belum belajar secara kolaboratif tanpa ada saling tukar menukar pikiran, contoh nampak dari siswa yang pintar atau memiliki kemampuan lebih. Setelah mereka memperoleh pelajaran dari guru dan memahami konsep yang diberikan, mereka tidak mau membimbing atau mengajar temannya yang kurang memahami konsep. Selain itu siswa yang kurang dalam memahami konsep juga masih enggan untuk bertanya kepada guru atau bertanya kepada temannya walaupun tidak bisa memecahkan masalah yang diberikan, sehingga siswa yang kurang atau yang minim pengetahuannya tetap tidak ada perkembangannya.

Permasalahan tersebut berdampak pada pemahaman konsep belajar matematika yang masih memiliki nilai rata-rata dibawah Kriteria Ketuntasan Minimal (KKM). Perolehan nilai dari hasil belajar matematika pada siswa SMAN 7 Mataram dapat dilihat pada Tabel 1.1 dibawah ini.

Tabel 1.1. Data Hasil Nilai Ulangan Harian Siswa Materi Bangun Ruang pada mata pelajaran matematika siswa kelas XI IPA SMAN 7 Mataram Tahun Pelajaran 2018/2019.

\begin{tabular}{|c|c|c|c|}
\hline \multirow{2}{*}{ No } & \multirow{2}{*}{ Kelas } & \multicolumn{2}{|c|}{ Nilai Tengah Semester } \\
\hline & & KKM & $\mathrm{KK}(\%)$ \\
\hline 1. & XI IPA 1 & 70 & $86 \%$ \\
\hline 2. & XI IPA 2 & 70 & $60 \%$ \\
\hline
\end{tabular}




\begin{tabular}{r|l|l|l}
\hline 3. & XI IPA 3 & 70 & $69 \%$ \\
\hline 4. & XI IPA 4 & 70 & $88 \%$ \\
\hline 5. & XI IPA 5 & 70 & $89 \%$ \\
\hline 6. & XI IPA 6 & 70 & $70 \%$ \\
\hline
\end{tabular}

Sumber: Data Hasil Belajar Matematika di SMAN 7 Mataram

Berdasarkan tabel 1.1 menunjukkan bahwa ketuntasan klasikal yang diperoleh setiap kelas XI IPA diatas $85 \%$ kecuali XI IPA 3 dan XI IPA 2 adalah 60\%, dimana presentasi ketuntasan klasikal kurang dari 85\%. Hal ini menunjukkan hasil belajar matematika siswa yang sangat rendah. Kriteria ketuntasan minimal (KKM) di SMAN 7 Mataram adalah 70 .

Melihat hal ini, perlu diupayakan sebuah model pembelajaran agar dapat mengoptimalkan proses belajar mengajar yaitu mengaitkan dengan contoh nyata berupa alat peraga 3 dimensi yang terbuat dari kertas duplek, sehingga mampu membuat siswa paham dengan konsep matematika karena lebih realistik. Kertas duplek merupakan suatu kertas yang dapat digunakan sebagai salah satu bahan yang tepat untuk pembuatan alat peraga matematika. Kertas duplek sendiri memiliki ciri yang tebal namun mudah untuk dibentuk sesuai ukuran yang telah ditentukan.

Salah satu model pengajaran yang dapat digunakan untuk memperbaiki kualitas proses dan hasil belajar adalah pembelajaran matematika melalui penerapan model pembelajaran Example Non Example. Pendekatan pembelajaran Example Non Example merupakan salah satu pendekatan Group investigation dalam pembelajaran kooperatif yang dirancang untuk mempengaruhi pola interaksi siswa dan meningkatkan perolehan hasil akademik. Tipe pembelajaran ini dimaksudkan sebagai alternatif terhadap model pembelajaran kelas tradisional dan menghendaki siswa saling membantu dalam kelompok kecil dan lebih dicirikan oleh penghargaan kooperatif daripada individu. (Hamdani, 2011: 3). Pendekatan pengajaran Tipe Example Non Example bertitik tolak dari hal-hal yang riil bagi siswa, menekankan keterampilan 'process of doing mathematic', berdiskusi dan berkolaborasi, berargumentasi dengan temen sekelas sehingga mereka dapat menemukan sendiri (student inveting sebagai kebalikan dari teacher telling) dan pada akhirnya menggunakan matematika itu untuk menyelesaikan masalah baik secara individu maupun kelompok. (Jarmita dan Hazami, 2013:212-222).

Model pembelajaran Tipe Example Non Example ini dapat digunakan untuk meningkatkan kemampuan penalaran matematika siswa dan meningkatkan minat dan hasil belajar matematika siswa yang sudah terbukti dari beberapa penelitian antara lain: Menurut hasil penelitian dari (Saputri, 2018:186) bahwa terdapat pengaruh pendekatan Tipe Example Non Example sehingga dapat meningkatkan kemampuan penalaran matematika siswa, karena dalam pendekatan ini soal yang diberikan dikaitkan dengan kehidupan sehari-hari siswa, Keberhasilan model Pembelajaran Tipe Example Non Example juga dapat dilihat dari hasil penelitian (Darmawati, dkk 2017:99) mengatakan bahwa Penerapan model Tipe Example Non Example dapat meningkatkan minat dan hasil belajar matematika siswa kelas VIII C MTs.AL Ma'arif NU Sinah tahun pelajaran 2016/2017'. Hal ini dapat dilihat dari angket minat siswa setelah melaksanakan model pembelajaran Tipe Example Non Example menjadi baik.

Berdasarkan latar belakang yang telah dipaparkan, maka peneliti tertarik untuk melakukan penelitian dengan judul "Pengaruh Model Pembelajaran Kooperatif Tipe Example Non Example Berbantuan Kertas Duplek Terhadap Peningkatan Pemahaman Konsep Bangun Ruang"

\section{METODE}

Penelitian ini merupakan penelitian Quasi Eksperimental. Desain penelitian yang digunakan adalah Postest Only Control Design, desain penelitian ini terdiri dari satu atau beberapa kelompok eksperimen dan satu kelompok kontrol. Kelas control tidak dapat 
berfungsi sepenuhnya untuk mengontrol variabel-variabel luar yang mempengaruhi pelaksanaan eksperimen (Sugiyono, 2012). Untuk lebih jelasnya dapat dilihat pada rancangan penelitian gambar 3.1

\begin{tabular}{|c|c|c|}
\hline Kelas & Perlakuan & Post-Test \\
\hline $\mathrm{E}$ & $\mathrm{X}$ & $\mathrm{O}_{2}$ \\
\hline $\mathrm{K}$ & $\mathrm{Y}$ & $\mathrm{O}_{2}$ \\
\hline
\end{tabular}

Gambar 3.1. Rancangan Penelitian

Keterangan :

E : Kelompok Eksperimen

K : Kelompok Kontrol

$\mathrm{X}$ : Pembelajaran dengan pendekatan example non example

$\mathrm{Y}$ : Pembelajaran dengan pendekatan metode ceramah

$\mathrm{O}_{2} \quad$ : Pemberian tes akhir (Sugiyono, 2012)

Didalam penelitian ini yang menjadi populasi adalah seluruh siswa kelas XI MIPA SMAN 7 Mataram, yang terdiri dari 5 kelas dengan jumlah siswa keseluruhan seperti pada tabel 3.3 berikut ini.

Tabel 3.3 Populasi Siswa Kelas XI Tahun Pelajaran 2018/2019

\begin{tabular}{|c|c|}
\hline Kelas XI & Jumlah Siswa \\
\hline XI IPA 1 & 35 \\
\hline XI IPA 2 & 35 \\
\hline XI IPA 3 & 35 \\
\hline XI IPA 4 & 33 \\
\hline XI IPA 5 & 35 \\
\hline XI IPA 6 & 35 \\
\hline Jumlah & 208 \\
\hline
\end{tabular}

Sumber. Arsip Guru Matematika SMAN 7 Mataram

Berdasarkan tabel di atas, jumlah kelas yang menjadi populasi adalah 6 kelas yang terdiri dari kelas XI dengan jumlah 208 siswa, maka diambil dua kelas sebagai sampel penelitian ini.

Untuk menentukan kelas eksperimen dan kelas kontrol dilakukan teknik undian, dari hasil undian menyatakan bahwa kedua kelas, kelas XI IPA 3 sebagai kelas eksperimen dan kelas XI IPA 2 sebagai kelas kontrol.

\section{HASIL DAN PEMBAHASAN \\ 1. Data Hasil Belajar Siswa}

Data dalam penelitian ini berupa data hasil belajar siswa yang ditunjukkan dengan nilai post test. Pengambilan data untuk nilai post test menggunakan instrument pengumpulan data yang berupa soal uraian sebanyak 5 soal yang sudah diuji validitas oleh beberapa validator.

a. Data Hasil Post test

Posttest (test akhir) diberikan setelah kedua kelas sampel diberikan perlakuan. Adapun hasil test akhir siswa untuk kedua sampel kelas dapat dilihat pada tabel berikut:

Tabel 4.1 Data Hasil Tes Akhir

\begin{tabular}{|l|l|c|c|}
\hline No & \multicolumn{1}{|c|}{ Data } & $\begin{array}{c}\text { Kelas } \\
\text { eksperimen }\end{array}$ & $\begin{array}{c}\text { Kelas } \\
\text { kontrol }\end{array}$ \\
\hline 1. & $\begin{array}{l}\text { Jumlah } \\
\text { siswa }\end{array}$ & 35 & 35 \\
\hline 2. & $\begin{array}{l}\text { Skor } \\
\text { maksimal }\end{array}$ & 100 & 90 \\
\hline 3. & $\begin{array}{l}\text { Skor } \\
\text { minimal }\end{array}$ & 70 & 60 \\
\hline 4. & $\begin{array}{l}\text { Nilai rata- } \\
\text { rata }\end{array}$ & 89 & 70 \\
\hline
\end{tabular}

Dari tabel diatas disimpulkan bahwa ada perbedaan nilai antara kelas eksperimen dengan kelas kontrol dimana hasil belajar siswa pada materi bangun ruang untuk kelas eksperimen yang dapat pengajaran dengan model kooperatif tipe Example Non Example lebih tinggi jika dibandingkan dengan kelas kontrol yang mendapat pengajaran dengan metode ceramah, dimana nilai rata-rata pada kelas eksperimen lebih tinggi dibandingkan dengan kelas kontrol. Nilai rata-rata eksperimen 89 dan nilai rata-rata kelas kontrol 70.

\section{Hasil Uji Hipotesis}

Sebelum uji hipotesis terlebih dahulu dilakukan uji prasyarat yaitu uji normalitas dan uji homogenitas hasil belajar siswa.

a. Uji Normalitas 
Uji normalitas dilakukan untuk mengetahui normal atau tidaknya distribusi data kedua kelas sampel. Uji normalitas berdasarkan nilai test akhir. Berikut hasil uji normalitas kelas sampel berdasarkan data tes akhir. Tabel 4.2 Hasil Uji Normalitas. Pada tabel ini menerangkan hasil uji normalitas pada kedua kelas sampel sebagai syarat untuk menguji hipotesis.

\begin{tabular}{|c|c|c|c|}
\hline \multicolumn{4}{|c|}{ One-Sample Kolmogorov-Smirnov Test } \\
\hline & & \begin{tabular}{|c|} 
EXPERIMEN \\
T_CLASS \\
\end{tabular} & $\begin{array}{c}\text { CONTROL_- }^{-} \\
\text {CLASS }\end{array}$ \\
\hline \multicolumn{2}{|l|}{$\mathrm{N}$} & 35 & 35 \\
\hline \multirow[t]{2}{*}{ Normal Parameters ${ }^{\mathrm{a}}$} & Mean & 90.4286 & 64.0000 \\
\hline & Std. Deviation & 5.19777 & 6.83847 \\
\hline \multirow{3}{*}{$\begin{array}{l}\text { Most } \\
\text { Differences }\end{array}$} & Absolute & .324 & .349 \\
\hline & Positive & .219 & .349 \\
\hline & Negative & -.324 & -.279 \\
\hline \multicolumn{2}{|l|}{ Kolmogorov-Smirnov Z } & 1.919 & 2.066 \\
\hline \multicolumn{2}{|l|}{ Asymp. Sig. (2-tailed) } & .001 & .000 \\
\hline
\end{tabular}

a. Test distribution is Normal.

Berdasarkan hasil posttest pada siswa kelas eksperimen dan kelas kontrol dilakukan uji normalitas data. Pada tabel di atas untuk menentukan data bersifat normal atau tidak adalah nilai asymp. sig. (2-tailed). Pada kelas eksperimen diperoleh nilai asymp. sig. (2tailed) adalah 0,001 dengan $\mathrm{dk}=5 \%(0,05)$ pada taraf kepercayaan 95\%. Hal ini menunjukkan bahwa nilai asymp. sig. (2-tailed) $<0,05$ dengan demikian dapat disimpulkan bahwa data posttest pada kelas eksperimen berdistribusi normal. Sedangkan pada kelas kontrol diperoleh nilai signifikan data yakni nilai asymp. sig. (2-tailed) adalah 0,000 dengan $\mathrm{dk}=5 \%(0,05)$ pada taraf kepercayaan $95 \%$. Hal ini menunjukkan bahwa nilai asymp. sig. (2-tailed) $<0,05$ dengan demikian dapat disimpulkan bahwa data posttest pada kelas kontrol berdistribusi normal. Data berdistribusi normal menunjukan bahwa data tersebut memiliki sebaran data yang merata sehingga data posttest berdistribusi normal.

a. Uji homogenitas

Uji homogenitas dilakukan untuk mengetahui apakah suatu kelompok memiliki varians yang sama diantara anggota kelompok tersebut. Berdasarkan hasil perhitungan dengan menggunakan SPSS 16.0 for windows.
Tabel 4.3 Hasil Uji Homogenitas. Pada tabel ini menerangkan hasil uji homogenitas pada kedua kelas sampel sebagai syarat untuk menguji hipotesis.

Test of Homogeneity of Variances

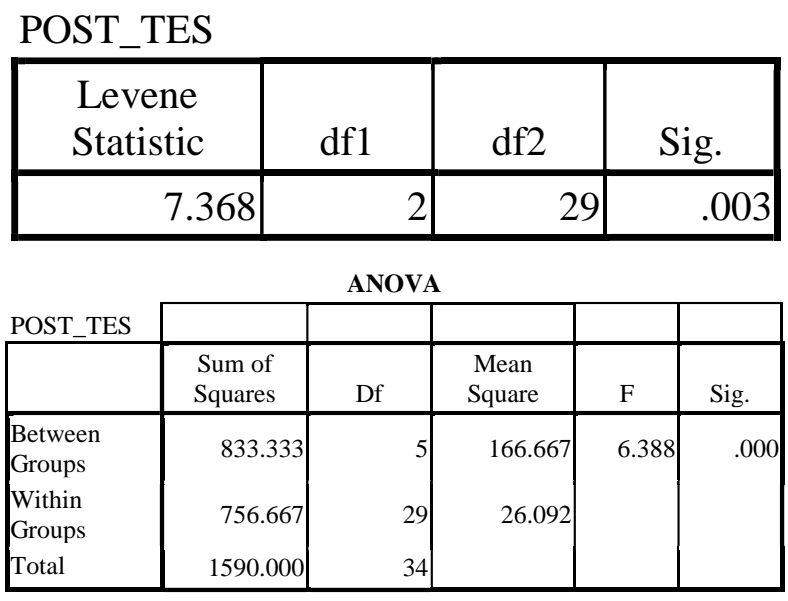

Berdasarkan hasil posttest pada siswa kelas eksperimen dan kelas kontrol dilakukan uji homogenitas data. Pada tabel diatas untuk menentukan data bersifat homogeny atau tidak adalah nilai sigtutel. Dapat diketahui perhitungan uji homogenitas pada kelas eksperimen dan kelas kontrol diperoleh nilai sigtutel adalah 0,000 dengan $\mathrm{dk}=5 \%(0,05)$ pada taraf kepercayaan 95\%. Hal ini menunjukkan bahwa nilai sigtutel $<0,05$, dengan demikian dapat disimpulkan bahwa data posttest pada kelas eksperimen dan kontrol mempunyai varians yang homogen. Varians yang homogeny menunjukan bahwa tingkat pemahaman konsep siswa tersebut sama, sehingga dikatakan bahwa kelas eksperimen dan kelas kontrol memiliki tingkat pemahaman konsep yang hampir sama.

a. Hasil Hipotesis (t-tes)

Uji hipotesis digunakan untuk menguji kebenaran suatu pernyataan secara statistik dan menarik kesimpulan apakah menerima atau menolak pernyataan tersebut. Hipotesis yang diuji adalah berupa $\mathrm{H}_{\mathrm{a}}$ (ada pengaruh metode Kooperatif Tipe Example Non Example terhadap pemahaman konsep siswa kelas XI SMAN 7 Mataram tahun 2018/2019). Uji hipotesis (t-tes) digunakan untuk mengetahui pengaruh signifikasi terhadap koefisien 
korelasi. Uji t-tes dengan bantuan SPSS 16.0 for windows.

Tabel 4.3 Hasil t-tes .

\begin{tabular}{|l|r|r|r|c|}
\hline \multicolumn{1}{|c|}{ One-Sample Statistics } \\
\hline & \multicolumn{1}{c|}{$\mathrm{N}$} & Mean & $\begin{array}{c}\text { Std. } \\
\text { Deviation }\end{array}$ & $\begin{array}{c}\text { Std. Error } \\
\text { Mean }\end{array}$ \\
\hline $\begin{array}{l}\text { EXPERIMENT_C } \\
\text { LASS } \\
\text { CONTROL_CLA } \\
\text { SS }\end{array}$ & 35 & 90.4286 & 5.19777 & .87858 \\
\hline
\end{tabular}

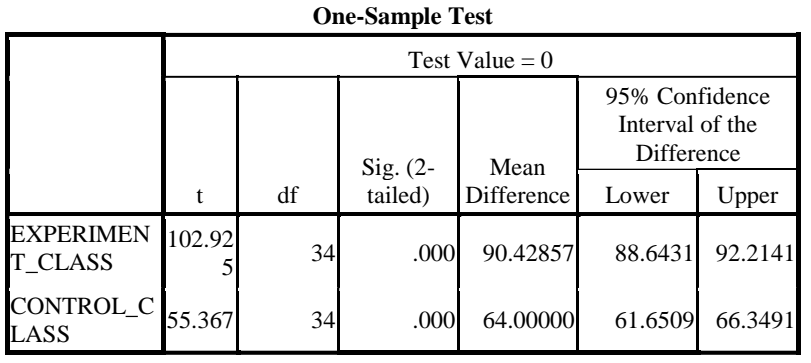

Dari data hasil analisis uji hipotesis diperoleh nilai signifikan sebesar 0,000 karena signifikan $<0,05$, maka dapat disimpulkan

bahwa $\mathrm{H}_{0}$ ditolah $\mathrm{H}_{\mathrm{a}}$ diterima. Artinya terdapat pengaruh penerapan pembelajaran Kooperatif Tipe Example Non Example terhadap pemahaman konsep siswa kelas XI IPA SMAN 7 Mataram.

\section{PEMBAHASAN}

Berdasarkan hasil penelitian diatas, dapat dilihat bahwa ada perbedaan secara signifikan yang dibuktikan dengan hasil uji (ttes) dimana signifikan $0,00<0,05$ maka penggunaan model pembelajaran kooperatif tipe Example Non Example dapat meningkatkan pemahaman konsep matematika pada materi Bangun Ruang siswa kelas XI IPA SMAN 7. Hal ini diperkuat dengan pendapat Ahmad (2002: 10) bahwa model pembelajaran kooperatif tipe Example Non Example dapat meningkatkan pemahaman konsep siswa dengan membentuk suatu kelompok. Jadi dapat disimpulkan bahwa pemahaman konsep di pengaruhi oleh penggunaan metode kooperatif tipe Example Non Example.

Model pembelajaran Example Non Example merupakan pendekatan pembelajaran dengan pola kelompok yang mengacu pada aktivitas pemeblajaran siswa yang menyenangkan dan menekan adanya interaksi aktif dari siswa dalam bertanya, untuk mengetahui pengaruh pembelajaran kooperatif tipe Example Non Example terhadap hasil belajar siswa setelah materi bangun ruang diterapkan, maka siswa diberikan tes (post test) pada kelas eksperimen dan kontrol. Adapun data kognitif siswa setelah perlakuan diberikan yaitu nilai rata-rata siswa kelas eksperimen 91\% sedangkan kelas kontrol nilai rata-rata $64 \%$.

Berdasarkan perbedaan nilai rata-rata ketuntasan hasil belajar kognitif pada kelas eksperimen dan kelas kontrol dapat dilihat perbedaan yang signifikan antara kedua kelas tersebut. Hal ini artinya perlakuan yang diberikan pada kelas eksperimen memberikan hasil yang lebih baik dibandingkan dengan kelas kontrol. Hasil ini menunjukan bahwa terdapat pengaruh yang signifikan efektifitas model pembelajaran kooperatif tipe Example Non Example dapat meningkatkan hasil belajar matematika pada materi pokok Bangun Ruang dibandingkan dengan metode Ceramah dan Tanya Jawab, walaupun demikian terdapat siswa yang memperoleh nilai yang rendah pada kelas eksperimen yakni 70. Kondisi inilah yang menunjukan bahwa masih ada siswa yang kemampuannya kurang untuk itu bagi siswa yang memiliki kemampuan kurang hendaknya guru aktif dalam proses pembelajaran dan hendaknya guru dalam mengajar dapat memberikan bimbingan secara individual sehingga pembelajaran dengan model kooperatif tipe Example Non Example dapat lebih mengefektivkan siswa dalam belajarnya.

Hasil dari penelitian ini dapat disimpulkan bahwa model pembelajaran kooperatif tipe Example Non Example lebih baik dari model pembelajaran konvensional jika diterapkan dalam proses pembelajaran khususnya pada materi bangun ruang. 


\section{KESIMPULAN}

Berdasarkan hasil analisis data dan pembahasan maka dapat disimpulkan bahwa ada pengaruh model pembelajaran kooperatif tipe Example Non Example berbantuan kertas duplek terhadap peningkatan pemahaman konsep bangun ruang.

\section{SARAN}

a. Guru

Metode Example Non Example sebaiknya dapat digunakan oleh guru sebagai salah satu alternative untuk melaksanakan pembelajaran inovatif, agar siswa merasa senang dan lebih tertarik untuk mengikuti kegiatan pembelajaran. b. Peneliti

Untuk peneliti selanjutnya dapat mengembangkan metode Example Non Example dengan variabel yang berbeda, agar meneliti aspek-aspek yang belum terjangkau sehingga diperoleh hasil yang maksimal.

\section{DAFTAR PUSTAKA}

Afrilianto, M. 2012. Peningkatan Pemahaman Konsep Dan Kompetisi Strategis Matematis Siswa SMP Dengan Pendekatan Metaphorical Thinking: Jurnal Ilmiah Program Studi Matematika STKIP Siliwangi Bandung. 1 (2): 192-202.

Anita Lie, 2010. Metode Pembelajaran Kooperatif. Bandung: CV. Wacana Prima.

Awaludin, 2008.MetodePenelitian, Jakarta: Universitas Terbuka.

Huda, M. 2015. Cooperative Learning. Yogyakarta: Pustaka Pelajar.

IKIP Mataram. 2018. Pedoman Pembimbingan Penulisan Karya Ilmiah. Mataram: IKIP.

Kesumawati, N. 2008. Pemahaman Konsep Matematik Dalam Pembelajaran Matematika. Makalah Disajikan Pada Seminar Matematika dan Pendidikan Matematika, Universitas PGRI Palembang.
Mel Silberman, 2009. Pembelajaran Kooperatif, Jakarta: Usaha Nasional

Mulyati, 2006.Metode Pembelajaran. Bandung: CV. Wacana Prima

Sardiman, 2009.Interaksi dan Motivasi Belajar Mengajar. Jakarta: PT. Raja Grafindo.

Slameto, 2003. Belajar dan Faktor-faktor yang Mempengaruhinya, Jakarta: PT. Rineka Cipta.

Sugiono, 2010. Memahami Penelitian Kualitatif dan Kuantitatif. Bandung: PT. Alfabeta.

Suharsimi Arikunto, 2002. Prosedur Penelitian. Jakarta: PT. Rineka Cipta 